\title{
4
}

\section{PROCESOS DE SELECCIÓN DE PERSONAL EN LA ADMINISTRACIÓN PÚBLICA DE LA PROVINCIA DE BUENOS AIRES. UNA ELIPSIS AL RÉGIMEN DE CONCURSOS PARA EL ACCESO A LAS FUNCIONES JERARQUIZADAS}

\author{
Magdalena Gil García (•) \\ Universidad Nacional de La Plata / \\ CONICET (Argentina) \\ Ricardo S. Piana (•) \\ Universidad Nacional de La Plata (Argentina)
}

\section{RESUMEN}

La profesionalización del empleo público resulta central para el fortalecimiento de las instituciones públicas y el mejoramiento de su rendimiento. Si bien no hay un único mecanismo o vía para promoverla, existe consenso en que requiere la conformación de carreras basadas sobre criterios de mérito. El objetivo de este trabajo es contribuir al análisis de la situación en materia de profesionalización en el ámbito subnacional, a partir de la política de Procesos de Selección de Personal para la ocupación de cargos jerárquicos en la provincia de Buenos Aires. A través del análisis de fuentes primarias y secundarias, el artículo da cuenta que la política no ha logrado resolver el manejo discrecional de los nombramientos, persistiendo la politización de los cargos reservados a los funcionarios de carrera.

\section{PALABRAS CLAVE:}

empleo público, burocracias públicas, profesionalización, procesos de selección de personal, carrera administrativa.

\footnotetext{
(•) E-mail: magdalenagilgarcia@yahoo.com.ar

(••) E-mail: r_piana@yahoo.es
}

\begin{abstract}
Professionalization of public employment is central to the strengthening of public institutions and the improvement of its performance. Although there is not a single mechanism or way to promote it, there is a consensus that requires the creation of careers based on criteria of merit and technical competence. The objective of this paper is to contribute to the analysis of the professionalization situation in the subnational area, based on the Personnel Selection Processes policy for positions of hierarchy in the province of Buenos Aires. This work examined primary and secondary data sources, the results shows the persistence of certain discretionary practices, which can be considered as a sign of politicization of public employment.
\end{abstract}

\section{KEY WORDS :}

public employment, state bureaucracies, professionalization, selection process, career paths.

RECEPCIÓN : $10 / 08 / 18$

ACEPTACIÓN FINAL: $14 / 11 / 18$ 


\section{INTRODUCCIÓN}

El empleo público de la Provincia de Buenos Aires es un universo complejo y heterogéneo, puesto que abarca una diversidad de actividades y estructuras organizativas. Es además, el nivel subnacional que registra mayor cantidad de puestos de trabajo en el empleo público ${ }^{1}$. La Provincia no escapa a las fuertes presiones por modificar los resultados de sus políticas públicas siendo sus recursos humanos un blanco reiterado de las críticas y causa de explicación de esos resultados. Las sucesivas crisis económicas de los últimos años han moldeado una legislación laboral marcada por las excepciones que no han modificado sustancialmente las pautas normativas habidas desde el retorno a la democracia. Aún persiste el problema del incumplimiento de las normativas que regulan las carreras administrativas, convirtiéndose en un obstáculo para solucionar los déficits institucionales en materia de recursos humanos.

Para suplir los más de diez años de suspensión de los concursos previstos en la ley provincial de empleo público, Ley № 10.430, en el año 2005 se diseñó la política de los Procesos de Selección de Personal (PSP) para los cargos jerárquicos de Jefe de Departamento y Subdirector previstos en dicho marco normativo. Sin grandes modificaciones normativas en este tiempo, corresponde 
realizar un estudio de los resultados para descubrir si verdaderamente cumplió el objetivo de profesionalización del empleo público provincial. Por ello, en el presente artículo se analizará la política de los PSP, reflexionando sobre las características del diseño normativo, su implementación y su incidencia.

El estudio pretende realizar un análisis multidimensional de esta política. En primer lugar, se realizó una descripción de las normas de empleo público provinciales, en especial la Ley $N^{\circ} 10.430$ y su régimen de concursos para el acceso a ciertos puestos jerárquicos, las sucesivas normas de suspensión para finalmente estudiar la normativa modelo para los PSP. Se comparó luego las normas dictadas en alguna de las jurisdicciones de la provincia (Ministerios de Economía, Infraestructura y Trabajo) a fin de detectar desvíos respecto de la reglamentación general.

La información se complementó con la realización de entrevistas semiestructuradas a la funcionaria responsable del diseño originario ${ }^{2}$, a ex funcionarios responsables de las áreas de personal ${ }^{3}$ y a funcionarios y agentes de la entonces Dirección de Planeamiento y Desarrollo de Carrera y de la Dirección Provincial de Relaciones Laborales ${ }^{4}$, que participan en diferentes etapas de la política de PSP tales como la elaboración de Reglamentos, la intervención en expedientes, el asesoramiento técnico y las veedurías en la etapa de evaluación de competencias y méritos. Se buscó con ello indagar aspectos relativos a los objetivos iniciales así como las prácticas actuales y resignificación de los PSP5.

Finalmente, y a fin de estudiar la incidencia de esta política, con la poca información disponible se estudió su utilización sobre el total de puestos disponibles en los Ministerios arriba mencionados para lo cual hubo que realizar una reconstrucción de las estructuras administrativas más de diez años atrás ya que, a pesar de la profusión normativa en materia de estructuras en los últimos años, las normas remiten a otras anteriores.

Del análisis realizado podremos concluir que los PSP, surgidos en una coyuntura política y como mecanismo de excepción, se consolidaron como la única política meritocrática de acceso a ciertos cargos jerarquizados del empleo público en la provincia de Buenos Aires, pero que, por su baja incidencia y por el carácter interino del agente designado, no logran constituirse en una verdadera política de jerarquización del empleo público. 


\section{La PROFESIONALIZACIÓN EN EL EMPLEO PÚBLico}

Resulta un tópico en el debate político latinoamericano la necesidad de la profesionalización del empleo público. Sobre la base de un fuerte malestar social en los resultados del sistema político y burocrático, diversas oleadas modernizadoras en las últimas décadas han puesto uno de sus ejes en la necesidad de reformar el funcionamiento del sistema administrativo latinoamericano.

Con propuestas tan dispares y contradictorias como reducción del personal, procesos de selección para el ingreso y concursos, profesionalización de la carrera, recortes salariales, retiros voluntarios, gerencialización de la Administración, hasta transferencia de recursos humanos a otros ámbitos jurisdiccionales, los gobiernos de nuestra Región han adoptado políticas zigzagueantes en materia del empleo público. No podría ser de otra manera cuando discursivamente se apunta contra problemáticas tan dispares como el dimensionamiento del Estado, las duplicidades funcionales, los aparatos tecnocráticos enquistados, la opacidad administrativa, estructuras clientelistas, corporativistas, patrimonialistas, nepotistas y/o personalistas, además, claro está, de la identificación de lo público con la ineficiencia, ineficacia y la corrupción ${ }^{6}$.

No es el lugar para dar cuenta de las distintas orientaciones ideológicas, variantes técnicas y recetas que se han propuesto para la reforma estatal y administrativa, que van desde la consolidación del modelo burocrático, la recuperación del Estado hasta el laissez-faire neoliberal pasando por la reforma gerencial. Sí nos detendremos en un punto en el que parece haber consenso: la necesidad de la profesionalización del empleo público.

En este sentido, una referencia ineludible lo constituye la Carta Iberoamericana de la Función Pública (CIFP). Según los postulados de la CIFP se entiende por profesionalización a la "garantía de posesión por los servidores públicos de una serie de atributos como el mérito, la capacidad, la vocación de servicio, la eficacia en el desempeño de su función, la responsabilidad, la honestidad y la adhesión a los principios y valores de la democracia" (CLAD, 2003:3) 7 . Aunque la noción de profesionalización puede ser considerada como un término "catch all", puesto que incluye una diversidad de enfoques y estrategias para lograrla ${ }^{8}$, existe un discurso común que tiende a circunscribirla a la consolidación de sistemas de mérito en el empleo público (Martínez Puón, 2008). De manera, que se la ha vinculado con el cumplimiento de ciertos requisitos del modelo burocrático clásico, como la carrera administrativa y la contracara de la politización (Pacheco, 2008; Ramió y Salvador, 2018).

Diferentes investigaciones han relacionado a la profesionalización del empleo público con diversos resultados positivos, como el desarrollo económico, el 
mejoramiento del desempeño burocrático, disminución de la corrupción en las administraciones públicas, aumento de la confianza de la sociedad civil en las administraciones públicas, fortalecimiento institucional de las capacidades del Estado y el establecimiento de límites a la captura de las políticas públicas por parte de intereses corporativos (Evans, 1996; Evans y Rauch, 1999; Carlson y Payne, 2002; Longo y Ramio, 2008: Dahlström, Lapuente y Teorell, 2011). Sin embargo, son tan frecuentes las virtudes atribuidas a los sistemas basados en el mérito como las prácticas que tienden a eludirla.

En el caso de los Estados latinoamericanos la institucionalización un sistema burocrático weberiano en el empleo público fue un proceso fallido e inacabado. Así, aunque las normativas sobre la gestión del empleo público establezcan el ingreso competitivo y los sistemas de carrera profesional, las mismas evidencian una escasa implementación debido a la extensión del clientelismo y patronazgo. A partir de esta situación, se han analizado los diversos factores que operan como condicionantes de la débil institucionalización de los criterios de mérito. En este sentido, se ha puesto de relieve que la implementación de sistemas de mérito tropieza con diversos obstáculos como la persistencia del patronazgo y el clientelismo en la cultura política, la ausencia de coaliciones promotoras, los factores técnicos y la cultura organizacional del sector público (Geddes, 1994; Heredia, 2002; Longo y Ramio, 2008; Oszlak, 2009; Grindle, 2012 ). Con el objeto de resolver estos problemas y dotar a las administraciones públicas de nuevos marcos normativos, en las últimas décadas se implementado en la región reformas orientadas a la profesionalización del empleo público a través reformas a los regímenes de empleo público. Sin embargo, diversos estudios han puesto de relieve que la reforma de los marcos jurídicos no resulta suficiente para lograr cambios efectivos en materia de profesionalización (Oszlak, 2009; Cortázar Velarde, Lafuente y Schuster, 2014; lacovello y Chudnovsky, 2015; Chudnovsky y Dousset Farjat, 2016; Llano Carbonel, 2017) ${ }^{9}$.

En nuestro medio, la introducción de las técnicas del managment privado al sector público no han tenido los resultados esperados para la profesionalización del empleo, no sólo por la flexibilidad implícita en el modelo sino porque el gerencialismo ha puesto en crisis y evidencia las dicotomías de la racionalidad técnica y racionalidad política (Oszlak, 1999) de forma tal que las propuestas más actuales en la materia abogan no ya por limitar la interferencia de lo político, por imposible o utópico, sino más bien por limitar drásticamente el número de funcionarios y automatizar las tareas rutinarias (Ramió y Salvador, 2018). 


\section{EL CONTEXTO NORMATIVO DEL \\ EMPLEO PÚBLICO EN LA PROVINCIA DE BUENOS AIRES}

En la provincia de Buenos Aires el empleo público se estructura en un Estatuto General de aplicación para la mayoría de los agentes dependientes del Poder Ejecutivo, regulado por la Ley $N^{\circ} 10.430$ del año 1986, y en aproximadamente 18 regímenes especiales ${ }^{10}$ organizados de acuerdo a las áreas de desempeño y la especificidad de sus tareas. Dichas normativas regulan la relación entre la Administración Pública y sus empleados, determinando derechos, deberes y prohibiciones de los trabajadores del Estado. La mayoría de estos regímenes laborales son normas de naturaleza estatutaria emanadas de leyes, de modo que sólo algunas actividades minoritarias cuentan con Convenios Colectivos de Trabajo (CCT).

Como se ha señalado, el Estatuto dado por Ley $N^{\circ} 10.430$ es el régimen básico para el personal de la Administración Pública Provincial, ha sido modelo para el resto de las regulaciones de empleo público y funciona como norma supletoria en casos no contemplados por aquellos. Este reglamento regula la carrera con el mayor porcentaje de empleados públicos por detrás del Estatuto Docente. Este marco normativo presenta un modelo de organización del personal público que se sustenta en ciertos principios: el ingreso en base a la idoneidad e igualdad de oportunidades, estabilidad basada en el buen comportamiento, derecho a la carrera a través de un sistema de calificaciones y concursos que ponderan el mérito y el rendimiento satisfactorio (arts. 3, 19 entre otros de la Ley $\left.N^{\circ} 10.430\right)^{11}$.

La carrera administrativa se vincula con un sistema escalafonario que clasifica los diferentes cargos en seis agrupamientos (jerárquico, profesional, técnico, administrativo, obrero y servicio), organizados de acuerdo a las tareas, los niveles de escolarización formal alcanzados, y los niveles de responsabilidad y autoridad. Asimismo, estos agrupamientos se encuentran divididos en cinco clases, de acuerdo a los niveles de complejidad establecidos de las tareas y responsabilidades, y éstas en tres grados. Los Grados constituyen subdivisiones de las Clases, y definen las distintas instancias que conforman la complejidad de clase a la que pertenecen, en forma creciente en el ejercicio de la tarea, responsabilidad y autoridad (art. 137 Ley $\mathrm{N}^{\circ} 10.430$ ) y se relacionan con las 24 categorías salariales que componen el Escalafón.

Dicho diseño prevé un desarrollo horizontal en la carrera administrativa, denominado promoción el cual implica el pase del agente de un grado al inmediato superior dentro de su clase; y considera ascenso al movimiento vertical, es decir, el pase del agente de la clase a la cual pertenece al grado inicial de la clase inmediata superior de cada agrupamiento. Según el marco legal la 
promoción debería producirse cada dos años de modo automático en base a un proceso de calificación en el que el agente obtenga un puntaje que supere la media aritmética del agrupamiento en cuestión. Por su parte, el ascenso está supeditado a la existencia de la vacante y se accede a él mediante concurso interno. El marco legal establece además la conformación de una Junta de Calificaciones, Ascensos y Promociones la cual debe intervenir en ambos procesos. Para decidir sobre los ascensos, la evaluación debe tener presente las pautas del actual 157 de la Ley $N^{\circ} 10.430$, esto es, 1) calificación del agente, acumulada y del último período; 2) Puntaje acumulado por acciones de capacitación; 4) mérito; 5) examen de competencia y 6) antigüedad. Esta última sólo entra en consideración cuando hay paridad entre los concursantes en su evaluación. Queda claro entonces que el elemento de la antigüedad no es un valor en sí mismo, sino sólo contingente cuando la evaluación meritocrática arrojara una igualdad ${ }^{12}$.

De acuerdo a la normativa, las funciones jerarquizadas (Subdirector y Jefe de Departamento) serán asignadas a los agentes que resulten indicados en el primer término de la escala de méritos emergentes del concurso (artículo 160 Ley $N^{\circ} 10.430$ ), posición que podría perderse frente a una calificación insuficiente, pero salvo este caso, queda garantizada la estabilidad de las mismas. Como hemos brevemente desarrollado, a pesar de sus más de treinta años de vigencia con pocos cambios normativos sustanciales, la Ley $N^{\circ} 10.430$ prevé normas claras que configuran una carrera administrativa en base a la calificación y al concurso para la promoción y el ascenso, respectivamente. Sin embargo, muchas de las disposiciones normativas relativas a la carrera no se aplican o han sido suspendidas durante años ${ }^{13}$.

Entre las fuentes consultadas existe un consenso entre los diversos actores respecto de la situación de detenimiento de la carrera administrativa, pero con muy pocas referencias precisas que puedan justificar las causas.

En relación a las razones de esta suspensión, podemos identificar como primer hito normativo la sanción del Decreto de Necesidad y Urgencia №369/91, que el marco de las políticas de reforma estatal que también estaban dándose en la Nación, dispuso en la Provincia jubilaciones de excepción, supresión y congelamiento de vacantes ${ }^{14}$. Dicho decreto de necesidad y urgencia fue luego convalidado por Ley $\mathrm{N}^{\circ} 11.184$ llamada de "Reconversión Administrativa", la que reconoció la emergencia administrativa, financiera y económica, a la vez que determinó que el Poder Ejecutivo podría reasignar el destino del personal, disponer su rotación y/o reubicarlo en cargos de jerarquía igual o superior o en agrupamientos distintos al que se encuentra aun cuando se determinó 
que debería tener en cuenta para la reasignación o confirmación del agente la realización y aprobación de cursos y/o exámenes que él determine a través del órgano que establezca para tal fin (art. 11). Esta Ley fue sucesivamente prorrogada pero en 2003 la Corte bonaerense en autos «Fernández, Nilda c/ Municipalidad de la Costa s/Demanda contencioso administrativa" entendió que las prórrogas se habían extendido sólo hasta el 31 de diciembre de 1994. No mucho tiempo después y en el marco de otras de las cíclicas crisis decenales, se sanciona el Decreto $N^{\circ} 2658 / 00$ que fue extendido por sucesivos Decretos hasta fines de 2011, por el cual se suspendieron todas las designaciones de personal en las plantas permanente y temporaria de todas las jurisdicciones y organismos de la Administración Pública central y descentralizada, cualquiera fuere el régimen estatutario y el agrupamiento ocupacional, congelándose todas las vacantes existentes o que se produzcan en igual lapso ${ }^{15}$. Se ha señalado que la carrera está cancelada desde 1991, debido a que la "Reconversión Administrativa" habilitó las reubicaciones sin seguir los procedimientos determinado por la ley de empleo público (Subsecretaria de Gestión Pública, 2006). Sin embargo, otras fuentes consultadas ${ }^{16}$ indicaron que los mecanismos de calificación de personal y los llamados a concursos fueron abandonándose de modo progresivo desde la vuelta a la democracia sin responder a un hito institucional concreto.

Esta situación ha tendido a promover el estancamiento escalafonario de los agentes de la provincia de Buenos Aires, los cuales cuentan con escasas posibilidades de movilidad en la carrera administrativa, de modo que la mayoría de los cargos jerárquicos resultan ocupados sin mediación de proceso concursal a través de la propuesta del Director a cargo del área en base a diversos criterios: antigüedad en el área, conocimientos técnicos, confianza política y/o como resultado de presiones gremiales. Asimismo, debido al achatamiento de la pirámide salarial, la postulación a dichos cargos expresa en muchos casos la búsqueda de los trabajadores de una mejora salarial y no una genuina vocación de liderazgo.

Como consecuencia de esta situación en el año 2004 se iniciaron un conjunto de medidas orientadas a la recuperación de la carrera administrativa y su modificación, cuyas características analizaremos en el apartado siguiente. 


\section{LA POLÍtICA DE LOS PROCESOS DE}

\section{SELECCIÓN DE PERSONAL PARA CARGOS JERÁRQUICOS}

En el año 2004, en el contexto del impulso de ciertas políticas tendientes a la recuperación de la institucionalidad en la provincia de Buenos Aires, el espacio paritario representó una ventana de oportunidad, no sólo para la recuperación salarial sino también para el diseño de políticas de empleo público encaminadas a la reactivación de la carrera administrativa. En dicho ámbito se creó una Comisión de Carrera Administrativa, integrada por autoridades políticas, sindicatos estatales y técnicos de las áreas de recursos humanos con la finalidad de avanzar en el rediseño del sistema de carrera y la apertura de los concursos. Se buscaba saldar una deuda con los trabajadores del sector público cuyas carreras laborales se encontraban estancadas y sometidas a prácticas discrecionales basadas en el favoritismo y los criterios de confianza política.

En ese marco se elaboró y discutió un proyecto que establecía un nuevo modelo de carrera profesional administrativa basado en la valoración de competencias como requisitos de ingreso, ascenso y promoción. El sistema de carrera propuesto tendía a poner de relieve la valoración de los "conocimientos en acción" tanto provinieran de la educación formal o de la experiencia adquirida en la administración pública y otros espacios laborales; y se basaba en la descripción de puestos y competencias. Así, se tomó a las competencias ${ }^{17}$ como el criterio fundamental para determinar las capacidades requeridas para cubrir los puestos de trabajo, entendiendo a estas como el conjunto de saberes que las personas ponen en acción en situaciones laborales o sociales, que involucran valores, actitudes y conocimientos. Además, para el desempeño en la función pública, se distinguieron tres tipos de competencias: a) las ético-institucionales, referidas a los valores y concepciones de la persona respecto la sociedad y las instituciones, debiendo manifestarse un respeto por la democracia y un compromiso con el plan de gobierno; b) las técnico-profesionales, relativas a los conocimientos y destrezas específicas para el cumplimiento de las acciones correspondientes a un puesto de trabajo determinado; y c) las actitudinales, relacionadas a las actitudes y estrategias que las personas ponen en juego en su vínculo con el entorno laboral ${ }^{18}$. Como desarrollaremos posteriormente, el modelo buscaba conjugar los aportes de los sistemas gerenciales, a través de la gestión de competencias ${ }^{19}$, con la valoración del compromiso a los principios éticos del proyecto político estatal y sectorial, a partir de la identificación del componente ético-institucional.

Asimismo, y también en el ámbito paritario, se consensuó que la cobertura de los cargos jerárquicos de Jefe de Departamento y Subdirector de la Ley $\mathrm{N}^{\circ}$ 
10.430 se realizarían de modo interino, hasta la restauración de los mecanismos de concursos allí previstos, a partir de la política de los PSP retomando el modelo de gestión por competencias ${ }^{20}$.

Este proceso, que se diseñó desde la ex Dirección de Planeamiento y Desarrollo de Carrera, dependiente entonces de la Subsecretaría de la Gestión Pública, se inició a partir de junio de 2005 pero encontró base normativa en 2007 cuando se aprueba la "Guía Orientadora para la cobertura de cargos y funciones mediante procesos de Selección de Personal en la Administración Pública Provincial» (Resolución N 8/07 Subsecretaría de la Gestión Pública) ${ }^{21}$. Asimismo, la Guía Orientadora... entiende que es un importante avance para superar los nombramientos discrecionales y lo define como al uproceso participativo que se inicia en una jurisdicción a los efectos de la ocupación de cargos o la asunción de funciones específicas por parte de las personas que reúnen los requisitos y el perfil para dicho cargo o función en el marco de programas a implementar o servicios a brindar", definición que se conserva en la Guía Orientadora sancionada en 2011. Mientras que, en el último reglamento se fundamenta la importancia de la política en materia de profesionalización, puesto que favorece la selección de trabajadores idóneos para desempeñarse en los cargos de la administración pública.

Los PSP fueron diseñados como un procedimiento excepcional que pretendía eludir la ausencia de concursos debidamente ejecutados según el marco legal de empleo público. A diferencia de los concursos previstos en la Ley, los procesos de selección son interinos, y no cumplen con las calificaciones que exigían los primeros para la cobertura de cargos. La política era concebida como de carácter provisorio a la espera de la incorporación de los agentes temporarios, transitorios y contratados a la planta permanente del Estado ${ }^{22}$ y la aprobación de una nueva ley laboral en el ámbito provincial, lo que finalmente no sucedió ${ }^{23}$.

De esta manera, a diferencia de lo acontecido en el ámbito de la Administración Pública nacional, donde las recientes iniciativas de profesionalización orientadas a la reforma del sistema de carrera fueron plasmadas normativamente ${ }^{24}$, en el caso provincial se idearon mecanismos complementarios que funcionarían "como una instancia de tránsito hasta tanto se ordene definitivamente la carrera profesional administrativa en la Provincia" (Rodrigo y Palvi, s/f), pero que, como veremos, fungieron como un estrategia de profesionalización novedosa en el marco de las limitaciones a la carrera.

Ahora bien, ¿cómo se desarrollan estos procesos? ¿Cuál es su verdadera incidencia?, y lo más relevante, nos preguntamos si cumplió su objetivo.

PROCESOS DE SELECCIÓN DE PERSONAL EN LA AdMINISTRACiÓN PÚBLICA DE LA PROVINCIA DE BUENOS AIRES / Gil García y Piana 


\subsection{LA REGLAMENTACIÓN Y LA CONVOCATORIA DE LOS PSP}

Para que un organismo provincial pueda dar inicio a la política de los PSP es necesario que el área de recursos humanos haya aprobado un proyecto de reglamento que los regule, contando con el consenso de los representantes gremiales. Si bien el gobierno provincial elaboró desde sus áreas especializadas una Guía Orientadora que propone los lineamientos para diseñar los modelos de reglamentación, se reconoce que cada jurisdicción tiene autonomía en su definición atendiendo a las particularidades organizacionales. A pesar de esto, se exige que respeten los principios que regulan las leyes de empleo público garantizando la igualdad de oportunidades, la imparcialidad y la objetividad del proceso de selección. En la actualidad se han aprobado $19^{25}$ reglamentaciones, con sus respectivas modificatorias, para organismos centralizados y descentralizados de la Administración Pública Provincial. Inicialmente las primeras reglamentaciones aprobadas dieron cuenta de una tendencia al mimetismo normativo, pero en la actualidad se observan algunas diferencias significativas en las diversas etapas del PSP, de modo que "existen tantas realidades como organismos", como se señalaba en una entrevista. En este sentido, la falta de un organismo rector que regule la política, interviniendo en la elaboración de los diferentes reglamentos ha generado ciertos desvíos ${ }^{26}$ respecto del diseño formulado en las Guías orientadoras.

En el siguiente Cuadro presentamos un análisis comparativo de 3 reglamentaciones vigentes en materia de PSP de diferentes organismos, contrastándolas con el modelo propuesto por el Estado provincial, para dar cuenta de algunas de las diferencias más significativas detectadas. Si bien las dimensiones seleccionadas no son exhaustivas, por su relevancia permiten poner de relieve que las divergencias normativas atentan contra la coherencia interna del sistema de carrera de los agentes públicos encuadrados en el Estatuto General. 


\section{Cuadro 1.}

Análisis comparativo de reglamentaciones

\begin{tabular}{|c|c|c|c|c|}
\hline & Guías Orientadoras $^{27}$ & $\begin{array}{l}\text { Ministerio } \\
\text { de Economía }\end{array}$ & $\begin{array}{l}\text { Ministerio } \\
\text { de Infraestructura }{ }^{29}\end{array}$ & $\begin{array}{l}\text { Ministerio } \\
\text { de Trabajo }\end{array}$ \\
\hline $\begin{array}{l}\text { Aspectos } \\
\text { evaluados } \\
\text { y puntaje } \\
\text { asignado }\end{array}$ & $\begin{array}{l}\text { 1) Competencias ético- } \\
\text { institucionales (30\%), } \\
\text { 2) competencias técni- } \\
\text { co-profesionales, (40\%) } \\
\text { 3) competencias actitu- } \\
\text { dinales (30\%). }\end{array}$ & $\begin{array}{l}\text { 1) competencias ético } \\
\text { institucionales ( } 20 \%) \text {, } \\
\text { 2) competencias técni- } \\
\text { co-profesionales, } \\
(40 \%) \text {, } \\
\text { 3) competencias } \\
\text { actitudinales ( } 40 \%) \text {. }\end{array}$ & $\begin{array}{l}\text { 1) capacitación }(20 \%) \text {, } \\
\text { 2) antecedentes }(70 \%) \text {, } \\
\text { 3) mérito }(10 \%) \text {. }\end{array}$ & $\begin{array}{l}\text { 1) Competencias ético } \\
\text { institucionales ( } 40 \%) \text {, } \\
\text { 2) competencias } \\
\text { técnico-profesionales } \\
(30 \%) \text {, } \\
\text { 3) competencias } \\
\text { actitudinales (30\%). }\end{array}$ \\
\hline $\begin{array}{l}\text { Resolución } \\
\text { del PSP }\end{array}$ & $\begin{array}{l}\text { A partir del orden de } \\
\text { mérito de la evaluación } \\
\text { se establece una terna, } \\
\text { de la cual la autoridad } \\
\text { competente seleccio- } \\
\text { nará al candidato a } \\
\text { designar. }\end{array}$ & $\begin{array}{l}\text { Se establece un orden } \\
\text { de mérito, resultando } \\
\text { designado el aspirante } \\
\text { que logre el primer } \\
\text { lugar. }\end{array}$ & $\begin{array}{l}\text { Se establece un orden } \\
\text { de mérito, y se recono- } \\
\text { ce que puede resultar } \\
\text { designado un postulan- } \\
\text { te que no ocupe el pri- } \\
\text { mer lugar, con la debida } \\
\text { fundamentación. }\end{array}$ & $\begin{array}{l}\text { A partir del orden de } \\
\text { mérito de la evaluación } \\
\text { se establece una terna, } \\
\text { de la cual la autoridad } \\
\text { competente seleccio- } \\
\text { nará al candidato a } \\
\text { designar. }\end{array}$ \\
\hline $\begin{array}{l}\text { Plazo de } \\
\text { cobertura } \\
\text { del cargo }\end{array}$ & $\begin{array}{l}\text { No se realizan precisio- } \\
\text { nes respecto del plazo } \\
\text { de la cobertura interina } \\
\text { del cargo jerárquico }\end{array}$ & $\begin{array}{l}\text { La cobertura del cargo } \\
\text { tiene una duración de } \\
\text { tres años, luego de lo } \\
\text { cual se puede efectuar } \\
\text { una reválida o abrir } \\
\text { un nuevo proceso de } \\
\text { selección. }\end{array}$ & $\begin{array}{l}\text { No se realizan precisio- } \\
\text { nes respecto del plazo } \\
\text { de la cobertura interina } \\
\text { del cargo jerárquico. }\end{array}$ & $\begin{array}{l}\text { No se realizan precisio- } \\
\text { nes respecto del plazo } \\
\text { de la cobertura interina } \\
\text { del cargo jerárquico. }\end{array}$ \\
\hline
\end{tabular}

Fuente: elaboración propia en base a la normativa vigente y la información provista por la Dirección de Selección y Movilidad Interna

Respecto de la convocatoria, según la normativa vigente, cuando un cargo jerárquico queda vacante, la autoridad del área (de jerarquía no inferior a Director) tiene la facultad de solicitar a las máximas autoridades de la jurisdicción, que sea cubierto mediante proceso de selección ${ }^{31}$. Aun cuando los agentes interesados en el cargo vacante o los gremios pueden solicitarle inicio del proceso, éste depende de la voluntad política, que puede denegar o postergar dicho pedido. Esta facultad (y no la obligatoriedad), genera una evidente discrecionalidad en el procedimiento que ha limitado, a la fecha, la consolidación, aún con sus debilidades, de un proyecto de carrera.

Para solicitar la apertura del PSP la autoridad del área y las direcciones de personal deben especificar: la identificación del cargo dentro de la estructura 
orgánico-funcional, la confirmación del organismo pertinente de la existencia de crédito presupuestario para atender la erogación de la cobertura del cargo, y la definición institucional ${ }^{32}$.

Se entiende como requisitos generales a aquellos que exige la normativa vigente para el cargo vacante y como requisitos específicos a los que se relacionan con las acciones y tareas a realizar en el marco de las competencias jurisdiccionales. Esta facultad de fijar requisitos específicos resulta necesaria por las diversas especificidades de los puestos de trabajo ${ }^{33}$. Sin embargo, en la casuística esta la facultad regulatoria, aún para los requisitos generales, se ha usado con asiduidad para darle un carácter más cerrado a la convocatoria, limitándole la posibilidad de ascender en la carrera a determinados trabajadores que no cumplen con una antigüedad o posición escalafonaria determinada ${ }^{34}$. El proceso exige la descripción del puesto, con la identificación de los objetivos, tareas, procedimientos, recursos necesarios, condiciones de trabajo (horario a cumplir, lugar de trabajo, horarios no habituales, turnos extendidos, situaciones de riesgo, etc.), especificaciones (títulos, capacitaciones, experiencias certificadas, etc.), características del ambiente de trabajo, responsabilidades y relaciones con otros puestos. A partir de la descripción del puesto, debe identificarse el perfil requerido para su ocupación. La elaboración de este perfil resulta una pieza clave del proceso, ya que es utilizado para diseñar y determinar los criterios e instrumentos de evaluación. La mayoría de los Reglamentos jurisdiccionales siguen el modelo de gestión por competencias de la Guía Orientadora ... para realizar la descripción del perfil de puestos ${ }^{35}$. Sin embargo, esta descripción se suele elaborar en base a las acciones señaladas por el Decreto de Estructura de la Jurisdicción, lo cual tiende a que se privilegien los aspectos técnicos. Las Direcciones cuentan con la asistencia técnica de la Dirección de Selección y Movilidad Interna; sin embargo, en muchos casos la intervención de esta área ha quedado limitada a la realización de veedurías de los PSP post elaboración de los perfiles. En este sentido, la participación y asesoramiento en la elaboración de los perfiles serviría para corregir algunas dificultades que resultan determinantes y que afectan a todo el proceso ${ }^{36}$. Así también, se ha destacado que las direcciones de personal y recursos humanos de algunos organismos carecen de equipos de trabajos capacitados en estos aspectos técnicos, lo cual se vuelve un obstáculo para el desenvolvimiento del proceso. De esta manera, una dificultad de la política es que dichas áreas tienden a enfocarse en los aspectos normativos y los procesos administrativos, careciendo de profesionales formados en este tipo de estrategias y herramientas de gestión del empleo. 
Para comunicar la convocatoria se realizan diferentes estrategias y metodologías que varían según los organismos: sitio web, intranet, correo electrónico, medios gráficos y carteleras de la jurisdicción, etc. No obstante, se señalado que en algunos casos los medios de difusión no tienen en cuenta a los agentes que se encuentran en uso de licencias o en comisiones de servicio en otros organismos (Quintans y García, 2012).

\subsection{LA EVALUACIÓN DE COMPETENCIAS: INDICADORES, DISPOSITIVOS Y ACTORES}

La Unidad Técnica de Selección (UTS) ${ }^{37}$ tiene la función de determinar las herramientas de evaluación pertinentes en función de la descripción del puesto y del perfil del cargo realizado en la convocatoria y de elaborar el dictamen con el orden de mérito mediante la aplicación de los instrumentos y a partir de la deliberación y consenso de la mayoría. En la generalidad de los casos, los organismos conforman la UTS por: el/la titular de la Dirección Provincial o nivel orgánico equivalente de la estructura del área donde se encuentra la vacante a cubrir, el Director del área donde se cubre la vacante y el titular de la Dirección Delegada de la Dirección Provincial de Relaciones Laborales donde se realiza el concurso ${ }^{38}$. Algunos pocos organismos incluyen dentro de la UTS a los representantes gremiales ${ }^{39}$. Según Quintans y García (2012) se encuentran divergencias de opiniones respecto de la participación gremial en esta instancia. Por un lado, se considera que generan presiones con el objeto de extender beneficios a sus afiliados, mientras que otros consideran que la participación es positiva puesto que evita impugnaciones ${ }^{40}$.

Para que el proceso se realice en un marco de legalidad e imparcialidad, se conforma un grupo de veedores, integrado por la Dirección de Selección y Movilidad Interna (Ministerio de Jefatura de Gabinete de Ministros), la Dirección Provincial de Relaciones Laborales (Ministerio de Jefatura de Gabinete de Ministros), la Dirección Provincial de Promoción de los Derechos Humanos (Secretaría de Derechos Humanos) y los gremios del organismo (en caso de que no conformen la UTS). Aunque los aportes del veedor no resultan vinculantes, su participación permite que realicen sugerencias en la evaluación y garanticen la transparencia del proceso.

Como hemos señalado, muchos organismos realizan la evaluación según el modelo de competencias, de modo que en esta etapa ponderan mediante diversas herramientas su presencia de acuerdo al perfil de puesto. Si bien los criterios establecidos en los reglamentos no son homogéneos se observan algunas regularidades en la construcción de los indicadores. 
Según la última Guía orientadora en esta dimensión deben indagarse los valores y principios éticos del postulante, y su compromiso con las personas (respeto por los derechos humanos, aceptación de las diferencias, igualdad de oportunidades, etc.), el compromiso socio-cultural (valoración de las costumbres de diferentes grupos, respeto por los principios de equidad e inclusión social en las políticas), y compromiso institucional (defensa de las instituciones del Estado, y el organismo en que presta servicios). La introducción de esta dimensión fue destacada como uno de los aspectos innovadores de la política, mediante la cual se pretendía valorar el compromiso con los valores y principios del proyecto político estatal y sectorial, considerado como una variable escurridiza que escapa a los sistemas tradicionales de medición del comportamiento (Bernazza y Ronis, 2014) ${ }^{41}$.Desde esa perspectiva, esta innovación se inscribe en una serie de transformaciones respecto del paradigma del trabajo estatal, que ha sido definida en el ámbito local como la emergencia del homo militantis (Cao, Rey y Laguado, 2015), que combina la exigencia del mérito con una fuerte apelación al compromiso. Finalmente, también es posible considerar que la ponderación de dicha competencia da cuenta de la capacidad del trabajador de inscribir sus tareas cotidianas institucionalmente, es decir, en el marco de las normas generales y el plan estratégico del organismo en particular. Partiendo de esas consideraciones, la dimensión ético-institucional suele operacionalizarse para su medición en diferentes indicadores entre los que se destacan: los sumarios, el conocimiento de la estructura orgánico-funcional de la jurisdicción, el reconocimiento y adhesión al plan estratégico o institucional del organismo y el manejo de la normativa que regula el Estado Provincial. De manera que, en la implementación dentro de este componente se han tendido a privilegiar el conocimiento de aspectos normativos (relativos a la estructura interna del organismo y sus procedimientos administrativos) y la antigüedad en el área. En este sentido, pese a que en el sistema de la Ley 10.430 la antigüedad sólo debía ser tenida en cuenta en caso de paridad de puntajes, la misma suele introducirse en este tipo de competencia a través de la puntuación de la experiencia en la Dirección en que se concursa el cargo ${ }^{42}$. Aun cuando la valoración de la antigüedad da cuenta de una persistencia de una cultura administrativa de avance automático (lacovello, Zuvanic y Tomassi 2003), los argumentos de los actores entrevistados tienden a poner de relieve que resulta un indicador que da cuenta de la capacidad de adaptarse al entorno organizacional y su cultura, facilitando el manejo sociopolítico de situaciones conflictivas. Finalmente, siguiendo los lineamientos de la Comisión Mixta de Salud y Seguridad en el Empleo Público (CoMiSaSEP) ${ }^{43}$, algunos reglamentos minoritarios han 
determinado evaluar dentro de estas competencias el conocimiento básico de las normativas relativas a los riesgos de trabajo y la salud laboral.

En el caso de las competencias técnico-profesionales se evalúa el ajuste de los postulantes a los requerimientos técnicos específicos del puesto. Si bien los aspectos a evaluar y la metodología dependen de las características inherentes al puesto de trabajo, dentro de este tipo de competencias se pondera: el conocimiento del área y la tarea, el manejo de los procedimientos administrativos de acuerdo a la normativa y de los sistemas informáticos relevantes para el área, la capacitación relacionada con el puesto y la formulación de proyectos de gestión. Este tipo de competencias suele evaluarse a través de los análisis de antecedentes académicos o laborales, la presentación de proyectos, las evaluaciones teóricas escritas y pruebas de trabajo práctico.

Finalmente, a nivel de las competencias actitudinales se valoran las actitudes y estrategias que ponen en juego a partir de sus características de personalidad y su comportamiento en la situación laboral, evaluándose: la capacidad de liderar equipos de trabajo, el compromiso y la predisposición para la resolución de conflictos, iniciativa, la capacidad de comunicación, etc. Según la Guía Orientadora..., estas competencias deben ser evaluadas por trabajadores formados en recursos humanos, sociología y/o psicología laboral, a través de un proceso diagnóstico, utilizando herramientas propias de tales disciplinas como los test o las entrevistas ${ }^{44}$. Sin embargo, no todos los organismos cuentan con este tipo profesionales para la realización de dichas técnicas de evaluación, lo que requiere que convoquen a personal especializado de otras áreas o bien soliciten asistencia técnica a los organismos correspondientes.

De esta manera, se observa la existencia de una diversidad de herramientas y técnicas de evaluación, cuya elección depende de las competencias que se deben ponderar y de las características del perfil del puesto. En la mayoría de los casos, las herramientas de evaluación están previamente definidas en cada uno de los reglamentos de los organismos, y tienden a combinarse diferentes mecanismos.

La Guía Orientadora... sugiere ponderar las evaluaciones con los siguientes porcentajes: competencias ético-institucionales, 30\%; competencias técnico-profesionales, 40\%; competencias actitudinales, 30\%. A pesar de que las competencias técnico-profesionales sólo representan, en los diversos reglamentos, aproximadamente un $40 \%$ del puntaje total, en las entrevistas los informantes destacaron que, en muchos organismos, resulta el punto neurálgico de la evaluación. Así, en la implementación la evaluación continua enfocándose en aspectos relativos a la calificación técnica, y dentro de ella, los 
aspectos normativos e institucionales parecen ser definitorios. En este sentido, el componente ético-institucional parece haber perdido la centralidad que se le había concedido en su diseño inicial ${ }^{45}$.

\subsection{LA COBERTURA DE LOS CARGOS JERÁRQUICOS}

Luego del proceso de evaluación, se elabora y publica el dictamen de la UTS con el orden de mérito y la debida fundamentación. En caso de que no exista unanimidad, se eleva un dictamen de mayoría y uno o más en minoría. El proceso determina que luego de la notificación del orden de mérito, los aspirantes pueden presentar impugnaciones o solicitar revisión de los actos del proceso en trámite, en la forma y plazos establecidos.

Siguiendo las pautas de la Guía Orientadora... la mayoría de los reglamentos reconoce que del orden de mérito resultante, la autoridad competente podrá seleccionar a cualquiera de los candidatos ternados ${ }^{46}$; si es respecto del dictamen de minoría de la UTS, debe expresar las razones por las que desestima el de la mayoría. Sin embargo, también se reconoce que puede solicitar ampliación o aclaración del dictamen; dejar sin efecto la selección o declarar desierto el concurso con invocación de causa. Aun cuando en la implementación suela designarse al primer postulante resultante del orden de mérito, el sistema

propuesto combina la selección mediante criterios de méritos profesionales y de confianza personal o política, puesto que la decisión final es tomada por la autoridad respectiva. Respecto de este punto, en una de las entrevistas se puso de relieve que el modelo diseñado se basó ${ }^{47}$ en el Sistema Nacional de la Profesionalización Administración (SINAPA), que rigió para el ámbito nacional, y que creó los cargos de conducción denominados Funciones Ejecutivas (FE), que estipulaban una selección basada en el mérito y que culminaba en una terna de la cual la autoridad superior (política), escogía al designado ${ }^{48}$. Sobre este punto es importante señalar que, para autores referentes en la temática, la permanencia de criterios de confianza política expresa una politización en el empleo público, y es un indicador indirecto de inestabilidad en la conducción y falta de continuidad en la ejecución de políticas y planes de gobierno (Oszlak, 2001; lacovello, Zuvanic y Tomassi, 2003).

Cabe aquí recordar que la designación de los agentes es interina: ya desde el acto administrativo de convocatoria se debe señalar que la selección no genera derechos subjetivos para los participantes y que no tiene carácter formalmente vinculante. No hay previsiones en la Guía Orientadora... a este plazo, ni al proceso de reválida o evaluaciones de desempeño que garanticen 
el debido proceso a la hora de limitar las designaciones interinas. Respecto del carácter interino de las funciones, se ha señalado que era resultado una conveniencia normativa, ya que según el Estatuto vigente, la titularización sólo podría lograrse mediante los procesos de concursos, suspendidos al momento de implementación de la política ${ }^{49}$. Asimismo, como hemos señalado previamente, las entrevistas pusieron de relieve que el acuerdo a largo plazo era otorgar la titularidad de los cargos concursos cuando se hayan terminado de regularizar los ingresos del personal temporario y contratado a la planta permanente del Estado. Más allá de las explicaciones atribuidas al carácter interno de las funciones, en la actualidad la ausencia de pautas claras relativas a la duración en la ocupación del cargo y los mecanismos de evaluación, habilitan un manejo discrecional que puede constituir un obstáculo para el objetivo de profesionalización.

\subsection{ALGUNOS RESULTADOS DE LA EXPERIENCIA}

Según los datos informados por la Dirección de Selección y Movilidad Interna, entre 2013 y 2016, el área intervino en 316 veedurías de PSP para Subdirectores y Jefes de Departamento en diferentes Organismos de la Administración Pública provincial ${ }^{50}$. Sin embargo, resulta imposible a la fecha establecer la cantidad de cargos cubiertos mediante PSP y su porcentaje sobre el total de cargos jerárquicos, para analizar el grado de implementación. En efecto, la inexistencia de un registro centralizado de acceso público a los cargos creados por las estructuras provinciales dificulta realizar un análisis completo de los resultados de esta política. Por otro parte, los Decretos de estructura suelen desplazar en el tiempo la apertura y desagregación integral de la totalidad de la estructura orgánica funcional, esto es, cargos de Subdirectores y Jefes de Departamento, con lo cual hay que realizar una verdadera reconstrucción arqueológica de las instituciones pues otra de las prácticas ha sido la modificación parcial de las estructuras ${ }^{51}$.

Por ello, hemos tomado y reconstruido la experiencia, como muestreo, a través de los tres organismos que seleccionamos en el Cuadro I, esto es, Ministerio de Economía, Ministerio de Infraestructura y Ministerio de Trabajo, ya que por sus distintos fines y tamaño de sus estructuras entendemos son organismos relevantes. 


\section{Cuadro 2.}

Relevamiento de cargos jerárquicos y procesos de selección (2013-2016)

\begin{tabular}{lccccc}
\hline & & $\begin{array}{l}\text { Ministerio } \\
\text { de Economía }\end{array}$ & $\begin{array}{l}\text { Ministerio } \\
\text { de Infraestructura }\end{array}$ & $\begin{array}{l}\text { Ministerio } \\
\text { de Trabajo }\end{array}$ & Totales \\
\hline $\begin{array}{l}\text { Cantidad } \\
\text { de Cargos }\end{array}$ & \begin{tabular}{l} 
Subdirector \\
\cline { 2 - 6 }
\end{tabular} & $27^{52}$ & $3^{53}$ & $8^{54}$ & 38 \\
\hline $\begin{array}{l}\text { Jefe de De- } \\
\text { partamento }\end{array}$ & $410^{55}$ & $124^{56}$ & $85^{57}$ & 619 \\
\hline $\begin{array}{l}\text { Cantidad de } \\
\text { Veedurías } \\
\text { en PSP }\end{array}$ & \begin{tabular}{l} 
Subdirector \\
\cline { 2 - 6 }
\end{tabular} & $5^{58}$ & 2 & 1 & 8 \\
\hline pefe de De- & partamento & 32 & 11 & 12 & 55 \\
\hline Aplicación & & $8,46 \%$ & $10,23 \%$ & $13,97 \%$ & $9,58 \%$ \\
\hline
\end{tabular}

Fuente: elaboración propia en base a las normativas y los datos provistos por la Dirección de Selección y Movilidad Interna

\section{CONCLUSIONES}

Como hemos podido reconstruir, la Ley № 10.430 lleva más años de suspensión para el ingreso y el congelamiento de las vacantes ${ }^{59}$ y la aplicación de su sistema de asensos y promociones que en su cumplimiento íntegro, existiendo a su vez una superposición normativa sin coordinación que, en el contexto de las recurrentes crisis y emergencias económicas, dificulta su aplicación y conocimiento por los diversos actores vinculados al régimen del empleo público provincial. De este modo, el empleo público en la provincia se caracteriza por un incumplimiento básico de la Ley en las disposiciones relativas a la carrera administrativa, fundamentalmente en lo que refiere a los procesos de concursos, calificación y evaluación de desempeño, prevaleciendo las prácticas informales y discrecionales en la ocupación de cargos jerárquicos.

Las últimas normas impulsadas en materia de empleo público ${ }^{60}$ dan cuenta de la continuidad que tienen las políticas de emergencia, basadas en las estrategias de reducción de plantas de personal y de flexibilización laboral. Pero como hemos reconstruido, ya no hay memoria en los actuales actores provinciales de cuándo fue la última vez que se dieron concursos de ascenso y por qué se suspendieron. 
Frente a la suspensión de los concursos previstos en ley provincial de empleo público, desde hace al menos veinte años, la política de los PSP para la cobertura de los cargos jerárquicos interinos constituye una elipsis: quiere parecerse un concurso, toma los recaudos de un concurso pero no lo es ni en cuanto a la valuación de los méritos, ni en cuanto a sus garantías ni respecto a la universalidad ni a su estabilidad. En efecto, diseñada de manera provisoria a la espera de la reforma de la Ley $N^{\circ} 10.430$, se institucionalizó como el procedimiento para la cobertura de los puestos jerárquicos de Jefe de Departamento y Subdirectores. Si bien la política constituye un avance en materia de profesionalización, debido a que el proceso de selección se basa en criterios de méritos profesionales; es, finalmente una norma flexible ya que permite continuar con el régimen de discrecionalidad e interinato de las normas de excepción.

A partir del análisis pudimos dar cuenta que, aunque la política fue prevista para superar la arbitrariedad en los nombramientos, su trayectoria ha estado marcada por la existencia de prácticas que se desvían de dicho objetivo. En este sentido, consideramos que tanto el diseño normativo, su carácter no obligatorio, como sus vacíos y desvíos abren la puerta al manejo discrecional de la cobertura de los cargos. En efecto, hemos especialmente destacado que las diversas normativas aprobadas reservan márgenes de arbitrariedad a las autoridades políticas que tienen la capacidad de decidir (o no) la apertura del PSP, y de elegir a diferentes candidatos dentro de una terna, o bien dejar sin efecto la selección.

En relación a los vacíos normativos, hemos destacado la falta de precisiones necesarias respecto de la duración de la designación interina, y al proceso de reválida que garanticen el debido proceso a la hora de limitar las funciones.

Respecto de los desvíos de la norma, pudimos detectar la persistencia de prácticas discrecionales en aquellos PSP en los que se manipula la descripción del perfil del puesto ajustándolo a un candidato determinado. Sin embargo, el aspecto más destacado en este punto es que los PSP continúan teniendo un carácter marginal. Como hemos destacado en el Cuadro II en los Organismos relevados su utilización, en el período analizado, no llega al 10\% de los cargos efectivamente concursables y en algunos organismos es menor aún ${ }^{61}$. En este punto, consideramos que la falta de un organismo rector de la política sumado a la inestabilidad de las diversas estructuras organizativas relativas a la gestión del empleo público en el ámbito provincial, y su falta de jerarquización han tendido a debilitar la política de los PSP62. La completa descentralización del proceso contribuyó a generar una heterogeneidad entre las jurisdicciones, situación que puede debilitar la necesaria equidad e igualdad de oportunidades 
entre los trabajadores del Estado. De esta manera la política ha tenido un desarrollo diferencial según las áreas del Estado provincial, mostrando mayor avance y consolidación en aquellas jurisdicciones que a lo largo de su historia institucional han estado marcadas por la profesionalización de sus funciones, como el Ministerio de Salud ${ }^{63}$ y Economía.

\section{NOTAS}

${ }^{1}$ Según los datos del año 2018 del Ministerio de Producción y Trabajo, la cantidad de puestos de trabajo dependientes de la Provincia de Buenos Aires asciende a 575.309, por encima de la suma de los de la Ciudad Autónoma de Buenos Aires (195.789), Córdoba (136.708) y Santa Fe (173.940). Fuente: http://www.trabajo. gob.ar/downloads/estadisticas/empleopublico/ Seguimiento_del_empleo_publico_Provincial_5. pdf. Consultado 6/11/2018. Según la misma fuente, los empleados nacionales en el primer semestre de 2018 ascienden a un total de 702.826. Del Poder Ejecutivo nacional, el número global es de 397.215 empleados, aunque de la Administración Pública Central, sólo dependen sólo 42.574 siendo el mayor número el de las fuerzas armadas y de seguridad 226.847. Fuera del Poder Ejecutivo, las Universidades tienen 186.734 empleados, mientras que el Poder Judicial 32.312 y el Poder Legislativo 13.102 empleados. http://www.trabajo.gob.ar/ downloads/estadisticas/empleopublico/Seguimiento_del_empleo_publico_Nacional_4.pdf. Consultado: 8/11/2018. Ninguna de las dos series incluyen contratados, becarios, pasantes ni otras modalidades de vinculación.

${ }^{2}$ Entrevista realizada a Claudia Bernazza, Subsecretaria de Gestión Pública de la provincia de Buenos Aires entre 2004-2007. Fecha $8 / 06 / 2018$

${ }^{3}$ Tres ex Directores delegados de personal en los Ministerios de Trabajo, ARBA y Secretaría General. ${ }^{4} \mathrm{Se}$ trata de agentes públicos profesionales dependientes de la actual Subsecretaria de Capital Humano (Ministerio de Jefatura de Gabinete de
Ministros), cuyos datos no se exponen con el fin de garantizar el anonimato y la confidencialidad solicitada.

${ }^{5}$ Dado el heterogéneo sistema de reglas formales e informales que regulan la gestión del empleo público y ante la falta de un sistema de información centralizado, dichos agentes constituyen la memoria institucional de las iniciativas de profesionalización y esta estrategia de triangulación metodológica es la que nos permitirá estudiar la complejidad de la política.

${ }^{6}$ Sin embargo, y dado el consenso habido en la necesidad de un cambio en el funcionamiento de las Administraciones Públicas en el contexto de los grandes cambios políticos, sociales y tecnológicos de los últimos años entendemos que el mayor desafío que tienen hoy las administraciones se encuentra en revertir estos prejuicios. ${ }^{7}$ El CLAD continuó insistiendo en la necesaria profesionalización del empleo público. Así, en 2008 en la Carta Iberoamericana de Calidad de la Gestión Pública señaló que «es una fuente de legitimidad el ejercicio independiente de una función pública profesional, seleccionada bajo los principios de igualdad, mérito y capacidad, al servicio de un programa de gobierno resultante del proceso democráticon (Punto 5 Principio de Legitimidad Democrática); en su documento doctrinario titulado "Gestión Pública Iberoamericana para el siglo XXl» elaborado en 2010 señala que «En relación con la profesionalización de la función pública, los avances no han resuelto todos los problemas. Entre los puntos problemáticos que persisten se puede citar, en forma primordial, la dificultad para aumentar la calidad de la 
burocracia. La meritocracia no se agota en el concurso público, tema en el cual hubo mayor progreso en los últimos años. También se requiere la generación de un ambiente meritocrático en otros aspectos de la carrera. En este punto, hay tres cosas que son esenciales: motivación, capacitación y responsabilización de los gestores públicos" (CLAD: 2010:10).

8 Dentro de las diferentes estrategias se destacan: adopción de sistemas de alta dirección pública, la creación de cuerpos especiales basados en el mérito y la capacidad, el fortalecimiento de las áreas de capacitación, la evaluación del desempeño y el ordenamiento de la composición de los sistemas salariales (Longo y Ramió, 2008, Ramió y Salvador, 2018;).

9 Un estudio empírico realizado por el BID donde se realizó un seguimiento del índice del desarrollo del servicio civil en la región, en el período 20042013 , ha puesto en evidencia que si bien hay un leve progreso de tal índice aún se encuentran en un nivel bajo (BID, 2014).

${ }^{10}$ La contabilización es una elaboración propia a partir de los datos de la Subsecretaria de Capital Humano (https://www.gba.gob.ar/capitalhumano/ leyes_y_decretos) y el análisis normativo de Cabral y Schreginger (2009). Así incluimos dentro de los regímenes laborales del empleo público de la provincia de Buenos Aires los siguientes Estatutos y Convenios Colectivos de Trabajo: Estatuto General para el Personal de la Administración Pública Provincial (Ley $N^{\circ} 10.430$ ), Personal de las Policías (Ley $N^{\circ} 13.982$ ), Personal del Servicio Penitenciario (Decreto Ley $N^{\circ}$ 9.578/80), Investigador Científico y Tecnológico de la Comisión de Investigaciones Científicas (Decreto Ley $N^{\circ}$ 9.688/81), Carrera del Personal de Apoyo a la Investigación y Desarrollo Comisión de Investigaciones Científicas (Ley $\mathrm{N}^{\circ}$ 13.487), Personal de la Dirección de Vialidad (Ley $n^{\circ}$ 10.328), Personal de Autoridad del Agua, O.C.A.B.A. y S.P.A.R. (Ley N 10.384 ), Escalafón de la Defensoría del Pueblo (Ley $N^{\circ} 13.834$ y Acta Comisión Bicameral $\left.N^{\circ} 6 / 10\right)$, Personal Técnico Gráfico (Ley N 10.449), Carrera Profesional Hospitalaria (Ley No 10.471), Estatuto del Docente (Ley $N^{\circ}$ 10.579), Personal Artístico
(Ley N $\left.N^{\circ} 12.268\right)$, Docentes de Minoridad (Ley $N^{\circ}$ 10.648), Personal Transferido de Puertos (CCT $N^{\circ} 164 / 75 ; N^{\circ} 17 / 75$ y N²4/75), Personal Ferroviario (CCT No 433/75; $N^{\circ} 26 / 75$; N ${ }^{\circ} 21 / 75$ y $\left.\mathrm{N}^{\circ} 27 / 75\right)$, Personal Transferido de Astilleros (CCT N 91/75). Contabilizamos a los empleados del Banco Provincia quienes, aun cuando exista cierta ambigüedad en cuanto a los fines de su función, poseen un Estatuto específico y su relación de empleo público ha sido reconocido por diversos fallos de la Corte provincial (Cardozo Oscar Mauricio c/ Banco Provincia de Buenos Aires s/ Demanda Contenciosa", entre otras) y la Corte Nacional («Recurso de hecho deducido por la actora en la causa González Lorenzo Ramón c/ Banco de la Provincia de Buenos Aires $\mathrm{s} /$ demanda contencioso administrativa»). Sin embargo, como señalamos, la contabilización es aproximada pues no existe una base de datos con información confiable y unificada sobre estos aspectos.

11 Este estatuto operativiza la facultad constitucional de la Legislatura de organizar la carrera administrativa con las siguientes bases: acceso por idoneidad; escalafón; estabilidad; uniformidad de sueldos en cada categoría e incompatibilidades (artículo 103 inc. 12). A su vez, el art. 39 inc. 4 de la Carta magna local señala que la Provincia "garantiza a los trabajadores estatales el derecho de negociación de sus condiciones de trabajo y la substanciación de los conflictos colectivos entre el Estado Provincial y aquellos a través de un organismo imparcial que determine la ley". Este artículo es un claro ejemplo de este incumplimiento normativo en materia de empleo público pues este Organismo nunca fue creado por la Legislatura y las discusiones paritarias entre los empleados y el Ejecutivo son negociadas por la cartera laboral, que depende del Ejecutivo. 12 La evaluación incluye un examen de competencia para cargos que por su índole instrumental y carácter operativo requiera una demostración de su ejercicio. En ese caso, los elementos que se consideran para el ascenso tendrán, como máximo los siguientes porcentaje de incidencia en la calificación final: calificación hasta10\%, capacitación hasta 30\%, antecedentes hasta 
$20 \%$, mérito hasta10\% y examen hasta 30\%. En el caso que no se necesario un examen de competencia, los porcentajes son los siguientes: calificación 15\%, capacitación 40\%, antecedentes $30 \%$ y mérito $15 \%$. Estos porcentajes corrigen un defecto de presente en la anterior reglamentación, Decreto $n^{\circ} 1227 / 87$, pues ponderaban de esta manera: antigüedad: 10\%; mérito: 15\%; calificación 15\%; antecedentes 25\% y capacitación $35 \%$. Adviértase también que no estaba ponderado uno de los elementos que señala la ley, el examen de competencia, que si bien es para para cargos instrumentales $u$ operativos o excepcionalmente caso de empate, no podía desaparecer sin más.

${ }^{13}$ Como desarrollaremos a lo largo del artículo frente a la ausencia de concursos se idearon los Procesos de Selección de Personal, los cuales no están contemplados en el marco legal vigente para el empleo público.

14 Asimismo, determinó en su art. 38 que el Poder Ejecutivo podría recurrir a la instancia de la negociación colectiva, entre otras materias, a los asuntos referentes a carrera, agrupamiento, promoción, calificación, capacitación y derechos sociales politizando así este aspecto.

15 El Decreto $N^{\circ} 2658 / 00$ ha sido modificado y ampliado por los Decretos $N^{\circ} 2809 / 00, N^{\circ}$ 3167/00, N³477/05, N ${ }^{\circ} 3485 / 06$ y prorrogado en todos sus términos por Decretos $N^{\circ} 1842 / 01$, $\mathrm{N}^{\circ} 1581 / 02, \mathrm{~N}^{\circ} 1134 / 03, \mathrm{~N}^{\circ} 1473 / 04, \mathrm{~N}^{\circ}$ 3477/05, No3485/06, N³57/07B, No 4019/08 $\mathrm{N}^{\circ} 3550 / 09$ y N³964/10. A partir de entonces, surge con el Decreto $N^{\circ} 3 / 12$ otra política de restricción en materia de recursos humanos, limitando las comisiones en la Administración y absorbiendo las vacantes no utilizadas.

${ }^{16}$ Se realizaron consultas a profesionales que se desempeñaron en áreas de personal y recursos humanos de la provincia de Buenos Aires en el período de referencia.

17 La bibliografía especializada tiende a destacar que la noción se gestó en la década de los ochenta, dentro de un nuevo de paradigma de gestión de recursos humanos. Así, en el modelo de organización del trabajo taylorista-fordista, se hacía eje en la idea de calificación, en tanto conocimientos y habilidades técnicas específicas para el ejercicio de una función determinada. Esta noción fue reemplazada por la idea de competencia, las que resultan más complejas e involucran además formas de comportamiento, capacidades y actitudes que permiten un buen desempeño laboral (Drolas, 2010).

18 Subsecretaría de Gestión Pública (2006). Estos principios y recomendaciones también se plasmaron en documentos del Consejo Federal de la Función Pública del año 2006 (COFEFUP). Ver: http://www.claudiabernazza.com.ar/web/ documentos/cofefup.pdf

19 Según la CLAD (2016) diferentes países de la región han incorporado el modelo de gestión de competencias en la definición de perfiles, en la selección y el desarrollo de las personas, lo cual es considerado como un instrumento para la profesionalización de la función pública y la gestión del talento organizacional.

${ }^{20}$ Como se ha señalado, en un modelo de gestión por competencia existe una identificación de los requisitos necesarios en cada puesto de trabajo y su correlato en los perfiles de las personas habilitadas para desempeñarse en él.

21 Derogada y modificada por Resolución N³0/11, la cual aprueba la primera revisión de la misma. La segunda revisión del Reglamento fue realizada en el año 2015. Fuente: http://www.modernizacion.gba.gov.ar/expertos/sites/default/files/6\%20Gu\%C3\%ADa\%20 Orientadora\%20para\%20Procesos\%20de\%20 Selecci\%C3\%B3n\%20de\%20Personal\%20 para\%20web\%202015.pdf

22 En este sentido, se pretendía que el proceso sea incluyente, regularizando situaciones contractuales previas. En el ámbito paritario las autoridades políticas y los gremios habían acordado la incorporación progresiva a la planta permanente del Estado provincial de los contratados y trabajadores temporarios que tuvieran más de dos años de antigüedad. Como resultado de dicha medida se habría logrado la regularización de aproximadamente 10.000 trabajadores en 2006 (Gowland, Arrupe y Semino, 2009).

${ }^{23}$ En el período 2005-2009 hubieron propuestas de modificación integral de la Ley. De acuerdo a 
Villarroell, Echagüe y Volonté (2012) en el año 2008 se elaboró desde la Subsecretaria de Modernización del Estado un anteproyecto de reforma de la Ley, consensuado con otros organismos y los gremios. Según los autores, si bien sólo restaban discutir y elaborar las características del régimen disciplinario y de licencias y permisos entre otros, la comisión redactora dejó de funcionar en el 2009 debido al abandono de las autoridades políticas. ${ }^{24}$ Nos referimos a la implementación del Sistema Nacional de Profesión Administrativa (SINAPA) en el año 1991 y al Sistema Nacional de Empleo Público (SINEP) aprobado el año 2008. La bibliografía señala que aunque muestran debilidades en su implementación, generaron avances en el establecimiento de mecanismos de evaluación de desempeño e incentivos a la profesionalización y capacitación (locovello, Zuvanic y Tomassi, 2009; Dousset Farjat, y Chudvnosvky, 2016).

25 No tenemos datos de si estos reglamentos han tenido acuerdo o no de los gremios, tal como lo indica la Guía Orientadora... antes de su aprobación por la máxima autoridad de la Jurisdicción. ${ }^{26}$ Aun cuando en los proyectos de PSP intervienen la Dirección Provincial de Relaciones Laborales y la actual Dirección de Selección y Movilidad Interna, se ha puesto de relieve que las observaciones y sugerencias realizadas no siempre resultan incorporadas a los mismos. Asimismo, han destacado que en muchos casos no reciben comunicación formal de los reglamentos de PSP aprobados hasta que no son convocados a participar en calidad de veedores.

27 Resolución n 30/11, Subsecretaria de Modernización del Estado.

${ }^{28}$ Resolución n 18/17, Ministerio de Economía.

${ }^{29}$ La información de este reglamento fue provista por la Dirección de Selección y Movilidad Interna. Según informantes claves al momento de realizarse este artículo la citada repartición estaba trabajando en la modificación de su Reglamento de Procesos de Selección.

30 Resolución 273/09 y 33/12, Ministerio de Trabajo.

${ }^{31}$ El proceso requiere la confirmación de la Dirección General de Administración o quien haga sus veces, de la existencia de crédito presupuestario para atender la erogación que resulta de la cobertura del cargo;

32 Sobre esta última, la Guía... reconoce que «La Administración Pública expresa, en sus diferentes jurisdicciones, un proyecto político institucional y un modelo de gestión para llevarlo a cabo. Este proyecto institucional se enmarca en una concepción del desarrollo económico, social y cultural provincial y nacional"

33 Por ejemplo, el Ministerio de Economía que requiere que los postulantes sean agentes del agrupamiento profesional, con una instrucción o título profesionales específico cuando se trata de un área con un alto contenido técnico.

${ }^{34}$ A modo de ejemplo, la Secretaría General de la Gobernación determina que los aspirantes, cualquiera sea las características del puesto, deben cumplir como requisito general con 10 años de antigüedad en la administración pública provincial, de los cuales los 3 años últimos deben ser en la unidad orgánica a la que se postula y revistar en una posición escalafonaria determinada: pertenecer al agrupamiento jerárquico o a la clase A, 1 y 2 del resto de los agrupamientos (Resolución N²29/07).

35 De 19 reglamentos analizados, 13 de ellos se basan en el modelo de gestión por competencias. ${ }^{36} \mathrm{~A}$ modo de ejemplo, se ha señalado como una práctica marginal la manipulación en la elaboración de los perfiles de los puestos jerárquicos, buscando que los mismos se adecuen a determinadas personas seleccionadas de antemano. Más recurrente resultan las inconsistencias en el diseño de las convocatorias, en las cuales las competencias exigidas resultan de un carácter general, o poco adecuadas de acuerdo al puesto. ${ }^{37}$ En la normativa aprobada en el año 2011 son llamadas con Unidades de Selección, pero la Guía orientadora del año 2015, los reglamentos y la jerga habitual las designan como UTS.

${ }^{38}$ Asimismo, se determina que los mismos pueden ser representados por quienes designen de jerarquía no inferior al cargo motivo de la selección. ${ }^{39}$ De los 19 reglamentos analizados, sólo en 5 se incluye en la conformación de la UTS a los representantes gremiales (Comisión de Investigaciones Científicas, Ministerio de Infraestructura, el Institu- 
to de Previsión Social, Ministerio de Producción, Ciencia y Tecnología; Ministerio de Trabajo) En este sentido, debido la pluralidad sindical característica del sector público dichos reglamentos establecen que se designará un representante por cada gremio de actuación en el organismo particular. Dado que en algunos casos, existen hasta 4 organizaciones gremiales facultadas para participar, algunos reglamentos previeron que el puntaje debe ser negociada entre las mismas.

${ }^{40}$ Cabe señalar que en el ámbito nacional la intervención de las entidades gremiales se limita a la fiscalización del proceso. Puesto que, el Régimen de Selección de Personal para el Sistema Nacional de Empleo Público (SINEP) establece que la Unión del Personal Civil de la Nación (UPCN) y la Asociación de Trabajadores del Estado deben velar por la igualdad de oportunidades, asegurando la veeduría del proceso (Art. 35 Resolución 39/10, Secretaria de Gestión Pública).

${ }^{41}$ Como se puso de relieve en una entrevista "Esto fue mucho antes de que se hable de militancia en el Estado. Nosotros nos agarramos de la idea de competencias del mundo anglosajón (...) además de los saberes hay que tener saberes relacionales y actitudinales: capacidad de negociar, comunicar, conformar equipos. Pero suponete que tenemos todas las competencias al estilo anglosajón. Yo tengo un tipo re comunicador, negociador, y que sabe un montón, pero no cree en la salud pública, no lo puedo poner de director de un hospital. Hay un piso de derechos humanos, hay un piso de principios éticos que están en nuestra Constitución que ese trabajador tiene que adherir, si no estoy en un problema. Entonces le sumamos algo que hasta ahora era novedoso, que eran las competencias éticoinstitucionales. Es decir coherencia ética respeto del rol del Estado, respeto por la democracia y respeto por los derechos humanos; y en cada proceso de selección o concurso en particular el principio por los éticos de esa política sectorial" (fragmento de entrevista realizada a Entrevista realizada a Claudia Bernazza, Subsecretaria de Gestión Pública de la provincia de Buenos Aires entre 2004-2007. Fecha 8/06/2018).

42 A modo de ejemplo, puede citarse el Regla- mento de Procesos de Selección del Instituto de Previsión Social (Resolución 65/09 y 84/12), donde se considera que dentro de las competencias ético-institucionales deben evaluarse: la experiencia profesional en áreas relacionadas a la función: (cargos en áreas relacionadas a la función en otros organismo públicos, antecedentes en jefaturas o cargos superiores en puestos similares) y compromiso institucional (conocimiento sobre la Provincia, conocimiento sobre el Sistema de Seguridad Social Provincial, experiencia en la Dirección a la que pertenece el cargo que se concursa. (Anexo 1, Artículo 24). 43 La Comisión Mixta de Salud y Seguridad en el Empleo Público tiene por finalidad proponer políticas sobre las condiciones y medioambiente de trabajo en el Estado provincial y promover acciones de prevención y protección de vida de los trabajadores (Ley $N^{\circ} 14.226$ Art. 2). Fue creada en el año 2008, y se encuentra conformada por representantes estatales designados por el Poder Ejecutivo Provincial y representantes gremiales designados por los secretarios generales de cada uno de los gremios estatales. Esta temática, dentro de la evaluación de las competencias técnico profesionales, fue incorporada por Resolución N5/14 del entonces Secretario de Personal y Política de Recursos Humanos de la Provincia. http://www.siape.gba.gob.ar/rrhh/images/Manuales/Resolucion\%205\%202014.pdf

${ }^{44}$ En este sentido, la Guía Orientadora... señala a modo de ejemplo que "para un puesto de jefe de una oficina con atención al público, se evalúa su capacidad para coordinar personal a través de una técnica de assessment center, su manera de vincularse con las personas a través del Test de Relaciones Objetales, y su capacidad para organizar y planificar las tareas a través del Test Guestáltico Visomotor de Bender" (2015: 24). Fuente: http://www.modernizacion. gba.gov.ar/expertos/sites/default/files/6\%20 Gu\%C3\%ADa\%200rientadora\%20para\%20 Procesos\%20de\%20Selecci\%C3\%B3n\%20 de\%20Personal\%20para\%20web\%202015.pdf. Consultado10/11/2017.

${ }^{45}$ Este tipo de competencia ha perdido peso en su ponderación cuantitativa, dado que los últimos 
reglamentos aprobados le conceden sólo un 20\% del puntaje total (Ministerio de Economía y Arba). ${ }^{46}$ Organismos minoritarios como el Ministerio de Economía y Arba establecen en sus reglamentos que resultará seleccionado el aspirante que obtenga el primer lugar en el orden de mérito.

47 El modelo propuesto por SINAPA determinaba que en los cargos simples se debía respetar el orden de mérito y en el caso de las funciones ejecutivas se exigía la confección de una terna de la cual la autoridad superior podía escoger al designado (Salas, 2005).

48 Actualmente el SINEP también habilita la conformación de una terna a partir del orden de mérito, pudiendo caer la designación en cualquiera de los ternados (Art. 64 Resolución n69/10, Secretaria de Gestión Pública).

49 Asimismo, fuentes consultadas destacaron que los concursos tienen como prerrequisitos la realización de los procesos de calificación del personal, los que siguieron suspendidos durante toda la etapa analizada.

50 Se realizaron 60 veedurías en 2013, 90 veedurías en 2014; 95 veedurías en 2015 y 71 veedurías en 2016. Las veedurías informas incluyen organismos muy dispares: C.U.C.A.I.B.A., Contaduría General de la Provincia, Dirección General de Cultura y Educación, Instituto Biológico, Instituto Cultural, Instituto de la Vivienda, Instituto de Previsión Social, IOMA, IPS, Ministerio de Asuntos Agrarios, Ministerio de Economía, Ministerio de Infraestructura, Ministerio de Justicia, Ministerio de Producción, Ministerio de Salud, Ministerio de Trabajo, Patronato de Liberados, Tesorería General de la Provincia.

51 Por ejemplo, para el período en el que tenemos datos, estuvieron vigentes para el Ministerio de Economía los Decretos N 92/11B y 48/15B. Sin embargo, en ambos se fijó que la desagregación integral de la totalidad de la estructura orgánico funcional fuera realizada con posteridad, fijándose a su vez que hasta dicho momento se mantendrían su vigencia aquellas unidades orgánicofuncionales con nivel inferior a Dirección oportunamente aprobadas que no fueran modificadas. Ahora bien, en ninguno de los casos se pudo identificar que esa desagregación se hubiere rea- lizado por lo cual hubo que reconstruir los cargos de Subdirector y Jefes de Departamento a través de diversos decretos de estructura derogados en cuanto a las Subsecretaría y Direcciones creadas pero no en lo que respecta a cargos inferiores. Dicha reconstrucción, para el caso de Economía, abarcó los siguientes decretos: № 4.536/94, № 1.040/96, No 258/02, No 786/03, No 400/05, $\mathrm{N}^{\circ} 1.887 / 06$, No $3.142 / 06$, No $206 / 07$, No $2.581 / 07$, No $2.881 / 07, N^{\circ} 1.826 / 08$, No $1.827 / 08$, No 103/09, № 1.977/09 y No 684/11. Para el dato del Ministerio de Trabajo, se tomó el Decreto $2126 / 10$ ya que los Decreto 49/15B y $1874 / 16$ no abrieron la estructura a los cargos inferiores, manteniendo la vigencia de las unidades orgánico-funcionales con nivel inferior a Dirección oportunamente aprobadas. En el caso del Ministerio de Infraestructura, para el período 2016 tenemos el Decreto 40/15B posteriormente derogado por 360/16. Sin embargo, ambos establecen postergan la apertura de los cargos y determinan que mantendrán su vigencia aquellas unidades orgánico-funcionales con nivel inferior a Dirección oportunamente aprobadas. De allí que hubo que retrotraerse al Decreto $N^{\circ} 1441 / 03$ y sus posteriores modificaciones: Decreto $\mathrm{N}^{\circ}$ 1982/06; Decreto $N^{\circ} 3620 / 08$; Decreto $N^{\circ}$ 72/12 y Decreto $N^{\circ} 719 / 15$.

52 De la Agencia Provincial de Desarrollo, 5 conf. Decretos N 1887/06; de la Sub. de Finanzas, 5 conf. Decreto N¹877/06; de la Sub. de Ingresos Públicos, 17, conf. Decreto N³142/06.

${ }^{53}$ Conf. Decreto $N^{\circ} 3620 / 08$ que introduce dichos cargos en la Dirección General de Administración. 54 Conf. Decreto N²126/10.

55 De la Sub. de Hacienda, 237, conf. Decreto N 4536/94; de la Ingresos Públicos, 132 conf. Decretos N³142/06 y N400/05; de la de Finanzas, 20 conf. Decreto $N^{\circ} 1877 / 06$, de la Agencia Provincial de Desarrollo, 20 conf. Decretos N $1887 / 06$; de la Unidad de Coordinación con Organismos Multilaterales de Crédito, 1 , conf. Decreto N684/11.

${ }^{56}$ Conf. Decreto № 1441/03, actualizado por Decreto $\mathrm{N}^{\circ} 3620 / 08$ y concordado con los Decretos $N^{\circ} 1982 / 06, N^{\circ} 72 / 12$ y No $719 / 15$.

57 Conf. Decreto $N^{\circ} 2126 / 10$. 
58 En el cálculo incluimos a dos Responsables Ejecutivos.

59 Esto obviamente no ha implicado que en todo este período no se hayan dado ingresos sino que han sido por Decretos de excepción y lo más grave es la precarización laboral de los ingresos dados con contratos en la planta transitoria, becas, pasantías, contratos de locación de obra, a través de organismos internacionales y universidades o recientemente, por una nueva Ley de Emergencia tecnológica y administrativa, Ley $N^{\circ} 14.815$, con contratos de servicios de monotributistas.

60 Nos referimos al congelamiento de las vacantes (Decreto N 618/16), la modificación de la Caja de Jubilaciones de los empleados del Banco Provincia (Ley $N^{\circ}$ 15.008), la habilitación de contrataciones de servicios de monotributistas (Ley de emergencia tecnológica y Administrativa, Ley $N^{\circ} 14.815$ prorrogada por Ley $\left.N^{\circ} 15.022\right)$ y el "reordenamiento y cuantificación de los recursos humanos", que "reordena" incentivando retiros voluntarios (Decreto N465/18).

${ }^{61}$ A modo de ejemplo, según los datos proporcionados por la Dirección de Selección y Movilidad Interna, en la Dirección General de la Cultura de Educación de la Provincia de Buenos Aires, uno de los ministerios con mayor dotación de personal en la provincia de Buenos Aires en el período 2013-2016 sólo se han realizado 4 procesos de selección para la cobertura de cargos jerárquicos. Según la reconstrucción de datos que hemos efectuado a partir de Quintans y García (2012), que relevaron la cantidad de PSP realizados hasta el año 2011 en base a un muestreo que incluye a los organismos más importantes, y los datos proporcionados por la Dirección de Selección y Movilidad Interna en base a los relevamientos de veedurías para el período (2013-2016), se habrían realizado aproximadamente en toda la Administración Pública 434 PSP, cantidad inferior a los cargos de Jefe de Departamento de los tres Organismos que hemos relevado. De todas formas, los datos deben ser considerados estimaciones y aproximaciones dado de que no existe un organismo rector que centralice las estadísticas de la política, y su impacto en la cantidad de cargos jerárquicos de carrera.

62 A modo de ejemplo la Dirección de Relaciones Laborales en la provincia en los últimos tres años tuvo dos denominaciones y estuvo en la órbita del Ministerio de Coordinación de Gestión Pública, del Ministerio de Economía y del Ministerio de Jefatura de Gabinete de Ministros.

63 Según los datos proporcionados por la Dirección de Selección y Movilidad Interna entre el año 2013-2016 se realizaron en el Ministerio de Salud 56 veedurías para los Procesos de Selección de Personal de cargos jerárquicos interinos.

\section{BIBLIOGRAFÍA}

Bernazza, C. y Ronis, M. (2014). "Proyecto de Nación y empleo público: cuando las convicciones cuentan». Disponible en http://www.claudiabernazza.com.ar/web/documentos/ bernazzaronis.pdf (Consultado 15/06/2018).

Banco Interamericano de Desarrollo (BID) (2014). "Al servicio del ciudadano: Una década de Reformas del Servicio Civil en América Latina (2004-2013)". Banco Interamericano de Desarrollo, Washington.

Carlson, I, y Payne, J.M. (2002). Estudio comparativo de estadísticas de empleo público en 26 países de América Latina y el Caribe. BID. Disponible en https://publications.iadb.org/bitstream/ handle/11319/5892/Estudio\%20Comparativo\%20de\%20Estad\%C3\%ADsticas\%20de\%20 Empleo\%20P\%C3\%BAblico\%20en\%2026\%20Pa\%C3\%ADses\%20de\%20Am\%C3\%A9rica\%20 Latina\%20y\%20el\%20Caribe.pdf?sequence=1\&isAllowed=y (Consultado 10/11/2018). 
CLAD (1998). "Una Nueva Gestión Pública para América Latina». Disponible en https://www. clad.org/images/declaraciones/ngpesp.pdf (Consultado 21/06/2018).

(2003). "Carta Iberoamericana de la Función Pública». Disponible en http://old.clad. org/documentos/declaraciones/cartaibero.pdf (Consultado 21/06/2018).

(2019). Gestión Pública Iberoamericana para el siglo XXI. Disponible en http://old.clad. org/documentos/declaraciones/gestion-publica-iberoamericana-para-el-siglo-xxi (Consultado 24/06/2018).

Cao, H., Rey, M., Laguado Duca, A. (2015). El Estado en cuestión. Ideas, política y Administración Pública en la Argentina (1960-2015). Buenos Aires: Prometeo.

Chudnovsky, M. y Doussett Farjat, M. (2016). "Cuando la falla en la implementación de las reglas se busca modificar con más reglas. La historia de las reformas del empleo público en Argentina». Desarrollo Económico 55 (217), 315-341.

Dahlström, C., V. Lapuente y J. Teorell (2011). "The Merit of Meritocratization: Politics, Bureaucracy, and the Institutional Deterrents of Corruption". Political Research Quarterly. 16, 2011: 1-13 (junio).

Drolas, A. (2010). "Del saber colectivo a las cualidades individuales. El debate sobre las competencias laborales». Convergencia Revista de Ciencias Sociales, (54), 35-51.

Evans, P. (1996). «El Estado como problema y como solución». Desarrollo Económico, 35(140), 529-562.

Evans, P. y Rauch, J. (1999). "Bureaucracy and Growth: A Cross-National Analysis of the Effects of Weberian State Structures on Economic Growth". American Sociological Review, 64(5), 748-765.

Geddes, B. (1996). Politician's Dilemma: Building State Capacity in Latin America. Berkeley: University of California Press.

Gowland, S.; Arrupe, M. G.; Semino, I. (2009). «Empleo público y negociación colectiva en la Provincia de Buenos Aires". Trabajo presentando en V Congreso Argentino de Administración Pública. Asociación Argentina de Estudios de Administración Pública.

Grindle, M (2012). Jobs for the Boys: Patronage and the State in Comparative Perspective. Cambridge, MA: Harvard University Press

Heredia, B. (2002). "La economía política de la reforma de sistemas de administración de personal público en América Latina: un marco de análisis». Documentos del Diálogo Regional de Políticas - BID. Disponible en https://publications.iadb.org/bitstream/handle/11319/4527/ La\%20econom\%C3\%ADa\%20pol\%C3\%ADtica\%20de\%20la\%20reforma\%20de\%20 sistemas\%20de\%20administraci\%C3\%B3n\%20de\%20personal\%20p\%C3\%BAblico\%20 
en\%20Am\%C3\%A9rica\%20Latina\%3a\%20Un\%20marco\%20de\%20an\%c3\%A1lisis. pdf?sequence $=2 \&$ isAllowed $=y$ (Consultado 10/06/2018).

lacovello, M.; Zuvanic, L.; Tomassi, M. (2003). «El servicio civil en Argentina: disfuncionalidades y núcleos centrales de abordaje». Trabajo presentando en II Congreso Argentino de Administración Pública. Asociación Argentina de Estudios de Administración Pública. Disponible en http://www.asociacionag.org.ar/pdfcap/2/lacoviello.pdf (Consultado 15/06/2018).

(2009). «El servicio civil en la Argentina: disfuncionalidades y núcleos centrales de su abordaje». En Guillermo Schweinhem, ed., Estado y administración pública: críticas, enfoques y prácticas en la Argentina actual. Buenos Aires. Asociación Argentina de Estudios en Administración Pública, págs. 175-200.

lacoviello, M. y Strazza, L. (2011). "De partidocracias rígidas a meritocracias flexibles en América Latinam. Documentos y Aportes en Administración Pública y Gestión Estatal, 11(16), 51-95. Disponible en http://www.scielo.org.ar/pdf/daapge/n16/n16a02.pdf (Consultado 15/06/2018).

lacoviello, M. y Chudnovsky, M. (2015). "La importancia del servicio civil en el desarrollo de capacidades estatales en América Latina». CAF Documento de Trabajo (2). Disponible en http://scioteca.caf.com/bitstream/handle/123456789/757/IACOVIELLO\%20\%26\%20 CHUDNOVSKY\%202014\%20CAF-Capacidad\%20Estatal\%20y\%20Servicio\%20civil. pdf? sequence $=1 \&$ isAllowed $=y$ (Consultado 15/06/2018).

Longo, F. y Ramió, C. (2008). La profesionalización del empleo público en América Latina. Barcelona: Fundación CIDOB.

Martínez Puón, R. (2008). "Tendencias actuales en la profesionalización de la función pública en Latinoamérica: buenas y malas noticias». Revista Enfoques: Ciencia Política y Administración Pública, 6(9), 127-143.

Oszlak, 0. (1999). "Quemar las Naves (o cómo lograr reformas estatales irreversibles)" en Aportes para el Estado y la Administración Gubernamental, Año 6. № 14. Primavera 1999.

(2001). "El Servicio Civil en América Latina y el Caribe: situación y retos futuros". Documento del Diálogo Regional de Política- BID. Disponible en https://publications.iadb. org/bitstream/handle/11319/2772/El\%20Servicio\%20Civil\%20en\%20Am\%C3\%A9rica\%20 Latina\%20y\%20el\%20Caribe\%3a\%20Situaci\%C3\%B3n\%20y\%20Retos\%20Futuros. pdf?sequence $=1 \&$ isAllowed=y (Consultado 11/07/2018).

(2009). "La profesionalización del servicio civil en América Latina: impactos sobre el proceso de democratización». Trabajo elaborado en el marco del Proyecto OEA-PNUD. La Democracia de ciudadanía: una agenda para la construcción de ciudadanía en América Latina. Disponible en http://unpan1.un.org/intradoc/groups/public/documents/UN-DPADM/ UNPAN040085.pdf (Consultado 10/06/2018). 
Pacheco, R. (2008). Brasil: politización, corporativismo y profesionalización de la función pública. En F. Longo y C. Ramió (eds.). La profesionalización del empleo público en América Latina (págs. 171-198). Barcelona, España: Fundación CIDOB.

Quintans, N. y García, M.E. (2013). «Procesos de selección de personal como política de empleo público: la experiencia de la provincia de Buenos Aires». Ponencia presentada en II Jornadas de Recursos Humanos en Instituciones Públicas. Disponible en http://www.modernizacion.gba.gov.ar/expertos/sites/default/files/PSP\%20como\%20politica\%20de\%20EP\%20 La\%20experiencia\%20de\%20la\%20Pcia.\%20de\%20BA\%20-Quintans-Garc\%C3\%ADa.pdf (Consultado 07/06/2018).

(2015). «El desafío de gestionar los Recursos Humanos en la Administración Pública Provincial». En Pagani, M.L., Payo, M. y Galinelli, B. (comp,), Estudios sobre Gestión Pública: aportes para la mejora de las organizaciones estatales en el ámbito provincial. Libro digital, Subsecretaria de Modernización del Estado. Disponible en http://www.modernizacion. gba.gob.ar/expertos/sites/default/files/Libro\%20Estudios\%20sobre\%20Gesti\%C3\%B3n\%20 P\%C3\%BAblica\%20-\%20ISBN\%20online.pdf (Consultado 07/06/2018).

Ramió, C. y Salvador, M. (2018). La nueva gestión del empleo público. Recursos humanos e innovación de la administración. Barcelona:Tibidabo.

Rodrigo, P. y Palvi, R. (s/f). "Negociaciones colectivas para la profesionalización del empleo público en la provincia de Buenos Aires». Documento de la Subsecretaria del Gestión Pública Provincia de Buenos Aires.

Salas, E. (2005). "Algunas experiencias y enseñanzas derivadas del proceso de rediseño y gestión del servicio civil en la Argentina." Trabajo presentado en el Foro Iberoamericano: Revitalización de la Administración Pública. Estrategias para la Implantación de la Carta Iberoamericana. México D.F., CLAD

Subsecretaría de Gestión Pública de la Provincia de Buenos Aires (2006). «Una Carrera para mejorar el Empleo Público. Documento no 6.3." Disponible en http://www.claudiabernazza.com.ar/ htm/memoria_ssgp/Contenido/Documentos/acciones1_empleo.html (Consultado 08/06/2018).

Villarroel, A. Echagüe, O., Volonté, J.P. (2012). "Las relaciones laborales en el sector público de la Provincia de Buenos Aires». Trabajo presentado en el II Congreso Nacional de Relaciones Laborales ACILTRHA / I Congreso Internacional de Integración Laboral Regional de América Latina UITEC. Buenos Aires: ACILTRHA.

PARA CITAR ESTE ARTÍCULO:

Gil García, M. y Piana, R.S. (2018). «Procesos de selección de personal en la administración pública de la provincia de Buenos Aires. Una elipsis al régimen de concursos para el acceso a las funciones jerarquizadas", DAAPGE, año 18, № 31 (jul-dic), 2018, pp. 81-110. Santa Fe, Argentina: UNL.

PROCESOS DE SELECCIÓN DE PERSONAL EN LA ADMINISTRACión PÚBLICA DE LA PROVINCIA DE BUENOS AIRES / Gil García y Piana 